\title{
Correction to: An Application of the Minority Stress Model in a Non-Western Context: Discrimination and Mental Health Among Sexual and Gender Minorities in Macedonia
}

\author{
Kristefer Stojanovski ${ }^{1}$ • Sasha Zhou ${ }^{2}$ - Elizabeth King ${ }^{1}$ - Jovana Gjorgjiovska ${ }^{3}$. \\ Antonio Mihajlov ${ }^{4}$
}

Published online: 8 November 2017

(C) Springer Science+Business Media, LLC 2017

\section{Correction to: Sex Res Soc Policy}

https://doi.org/10.1007/s13178-017-0299-4

The author names Kajevska 2016 and Bojan 2016 should read Miškovska Kajevska 2016 and Bilić 2016 respectively.

The online version of the original article can be found at https://doi.org/ 10.1007/s13178-017-0299-4

Kristefer Stojanovski

kstojan@umich.edu

Sasha Zhou

sashaz@umich.edu

Elizabeth King

ejking@umich.edu

Jovana Gjorgjiovska

jovana.gjorgjiovska@gmail.com

Antonio Mihajlov

amihajlov@s-front.org.mk

1 School of Public Health, Department ofHealth Behaviour and Health Education, University of Michigan, 1415 Washington Heights, Ann Arbor, MI 48109, USA

2 School of Public Health, Department of Health Management and Policy, |University of Michigan, 1415 Washington Heights, Ann Arbor, MI, USA

3 Youth Education Forum, Drenak 34-A, Skopje 1000, Macedonia

4 Subversive Front, Bulevar Kuzman Josifovski Pitu 19-5/28, Skopje 1000, Macedonia 